\title{
WIEDERAUFBAU NO BRASIL: RELAÇÕES ENTRE A ESCOLA DE ULM E O PROJETO PEDAGÓGICO DO MAM CARIOCA
}

\section{INTRODUÇÃO}

Em minha tese de doutoramento defendida em 2008, discuti a fundação do Museu de Arte Moderna do Rio de Janeiro (MAM), criado em 1948. Os resultados da pesquisa vêm sendo publicados amiúde e agora vêm editados na íntegra em livro que será lançado pela Editora da Fundação Getulio Vargas ainda em 2011. Embora, de fato, já tenha refletido sobre o tema em outras ocasiões, uma pequena reflexão, publicada como apêndice ao fim do livro merece ainda alguma consideração.

Ao analisar o Museu de Arte Moderna em seus primeiros anos de fundação, algumas hipóteses sobre o Museu eram recorrentes no levantamento bibliográfico sobre o tema e faziam eco a análises de instituições congêneres surgidas no Brasil em período mais ou menos semelhante, de modo que mereceram especial atenção à época da pesquisa. De um lado, a criação do Museu se explicava como parte de um inexorável processo de modernização por que passava o Brasil, em meados do século XX. No bojo da onda de industrialização ocorrida no pós-guerra, as instituições de cultura se criavam, na década de 1950, para se colocarem em compasso com nossa modernidade tardia. De outro lado, a segunda hipótese, não de todo desligada da primeira, supunha que a formação da instituição se enquadrava na moldura da substituição de importações e classificava o Museu como cópia inautêntica de instituições originárias do exterior.

Para colocar as hipóteses em discussão procurei entender em que medida esse processo de modernização era realmente necessário e em que medida as contingências que haviam dado lugar ao Museu não eram, elas mesmas, explicativas, não só de sua especificidade, mas também da construção de uma modernidade que se diz, e se faz, de vários modos. Dito de outro modo, procurei entender em que medida os debates e disputas constitutivos da criação do Museu também são responsáveis pela especificidade da instituição e do modo como a modernidade nele se manifesta.

Num primeiro momento, para discutir essa espécie de espírito de época que teria bafejado a todos no oportuno momento da industrialização, comparei 
o modo como os dois principais responsáveis pela criação do MAM - Raymundo Ottoni de Castro Maya e Niomar Moniz Sodré - conceberam o projeto do Museu e se puseram em conflito para impor seus respectivos modos de ver o mundo. Assim, procurei mostrar como a vitória de um modelo de museu com ênfase em exposições temporárias, em grandes fluxos de visitantes e em relação de proximidade com o público se fez, em verdade, em disputa com um modelo de museu de mecenato e colecionamento, lugar de memória pessoalizada, de culto à alta cultura e que, a seu modo, seria também bem-sucedido em outras instituições contemporâneas à fundação do Museu.

Num segundo momento, para discutir a ideia de cópia e americanização, comparei os museus de arte moderna do Rio de Janeiro e de Nova York, instituição que teria servido de modelo ao MAM carioca e que teria se colocado, de acordo com a bibliografia sobre o tema, como uma das vias de americanização da cultura brasileira no imediato pós-guerra. Olhando, contudo, a documentação coletada no MAM e no MoMA (Museum of Modern Art) sobre as relações entre os dois Museus, nota-se que foram de fato efêmeros os vínculos criados entre as duas instituições. A euforia inicial dos fundadores do MAM com o aceno de uma instituição do porte do MoMA nova-iorquino logo seria frustrada pela ajuda não tão generosa quanto se esperava, ou pelas restrições de uma instituição não tão grande quanto se queria. Para abrir a primeira mostra do MAM, o então diretor executivo Josias Leão escreveria a René D'Harnoncourt, diretor executivo do MoMA, requisitando a montagem de uma exposição de Braque, que deveria acontecer ainda ao fim de 1948. Em resposta, D'Harnoncour escreveria lamentando a impossibilidade de atender à solicitação; segundo ele, a instituição não dispunha de mais que seis obras do pintor e elas já seriam cedidas para uma exibição em Cleveland. D'Harnoncourt sugeria, então, uma mostra de arte dos séculos XIX e XX da coleção do MoMA. O silêncio de Josias Leão na resposta indicava que o preço, no entanto, estava provavelmente muito acima do orçamento pretendido. A exposição realizar-se-ia com obras das coleções particulares de membros do MAM e perceber-se-ia, afinal, que o Museu carioca teria que se sustentar por conta própria, dando-se por satisfeito com o Chagall doado por Nelson Rockefeller.

No entanto, a comparação com o MoMA, o diagnóstico da diferença e a eterna suspeita de ser o MAM cópia e instituição inautêntica nos levam a buscar a justificativa de sua especificidade novamente alhures. A hipótese insistente de influências internacionais e o caráter universalista deliberadamente proposto pela instituição conduzem, de fato, a buscar outros caminhos possíveis de pesquisa e comparação. As constantes referências à escola de Ulm (Santos, 1999; Nobre, 2006) e à inspiração que poderia ter proporcionado a seu caráter didático conduzem, com efeito, a uma possível comparação que procuro estabelecer neste artigo. A escola de Ulm aparece, com efeito, como importante referência para o modo como o MAM carioca construiu seu modelo pedagógico. 
Base, quem sabe, das profundas especificidades que marcaram a relação do Museu com seu público.

\section{A FUNDAÇÃO DO MAM DO RIO DE JANEIRO}

Fundado em 1948, o Museu de Arte Moderna do Rio de Janeiro foi criado em meio a uma vaga de instituições que foram construídas ao final da década de 1940 e início de 1950. Para fundar o Museu, formou-se, a partir de 1946, um grupo de colecionadores e apreciadores de arte, oriundos da elite da capital do país, com prestígio junto a instituições do Estado. Ao primeiro grupo de fundadores, formado principalmente por industriais, banqueiros e diplomatas, uniu-se um segundo grupo de empresários da imprensa carioca, com um perfil claramente empreendedor e distinto do grupo original de fundadores.

Do primeiro grupo, capitaneado por Raymundo Ottoni de Castro Maya, formou-se um projeto de colecionamento e exibição capaz de colocar o Museu em movimento. Entre os presentes à primeira reunião para a fundação do Museu de Arte Moderna do Rio de Janeiro, estavam empresários (Raymundo Ottoni de Castro Maya e o Barão de Saavedra), altos funcionários do Estado (Rodrigo Melo Franco de Andrade, Gustavo Capanema, Josias Leão), jornalistas e críticos de arte (Antonio Bento, Quirino Campofiorito, Lúcia Miguel Pereira), poetas e artistas (Manoel Bandeira, Raul Bopp, Maria Martins e Sotero Cosme).

Constituído nas redes de amizade e camaradagem que marcavam os círculos cosmopolitas da elite da capital, o grupo de fundadores, com amplos contatos na alta burocracia do Estado, mobilizou capital financeiro e social para criar o primeiro núcleo do acervo da instituição e as primeiras exposições do Museu. O acervo e a exposição permanente da primeira fase da instituição seriam compostos por doações e empréstimos de "amigos" que partilhavam, ou queriam partilhar, com Castro Maya, o "amor pela arte". Para a sede do Museu, as salas do Banco Boavista seriam cedidas pelas relações de amizade com o Barão de Saavedra.

$\mathrm{Na}$ sua primeira fase, setores da elite carioca viram na criação do MAM a possibilidade de associar a memória pessoal a um projeto empenhado na construção de um público de arte moderna e de uma imagem de cidade civilizada. Ao abrir a primeira exposição em sede própria, Castro Maya chamava a atenção para os objetivos de uma instituição "a fim de incutir no público o gosto pela arte, ou melhor, educá-lo a fim de compreender, ou pelo menos admitir, que os artistas de hoje não são mistificadores" (MAM, 1949). O projeto pedagógico da primeira hora se dirigia a um público que deveria "aceitar a nova mensagem num estado gratuito, penetrar na revolução dos métodos que o nosso século criou em todos os sentidos e procurar uma continuidade no processo de evolução" (MAM, 1949). 
A partir de 1951, no entanto, o convite para que Niomar Moniz Sodré se tornasse diretora executiva da instituição mudaria os rumos do Museu e rotinizaria um projeto bastante distinto daquele pensado por Castro Maya. Num pequeno cartão de visitas do Serviço de Patrimônio Histórico e Artístico Nacional (SPHAN), Rodrigo de Mello Franco escreveria em 12 de maio de 1950:

Além do assunto desses livros, o Josias aguarda muito uma resposta a respeito da substituição dele como diretor executivo do museu. Conheço muito mal o rapaz indicado, mas tenho a impressão de que seria preferível, no caso, a escolha de pessoa mais efetivamente influente aqui no Rio. A Niomar, mulher de Paulo Bittencourt, talvez nos pudesse prestar serviços mais valiosos, graças à sua influência no Correio da Manhã. Que é que você acha? Não sei, aliás, se ela aceitaria e se, neste caso, tomaria mesmo a sério a função (Andrade, 1950).

Ao que tudo indica, não só Castro Maya achou que a ideia era muito boa, como "a mulher de Paulo Bittencourt" em muito excedeu às expectativas dos primeiros fundadores do museu, chegando a ser mesmo - ironia do destino responsável pelo afastamento daqueles que a haviam inicialmente indicado. Niomar Moniz Sodré, então casada com o proprietário de um dos mais importantes jornais da cidade, iria se tornar, em 1951, diretora executiva do MAM e começaria uma dura peleja para impor sua marca ao Museu e se desvencilhar da aura aristocrática que, segundo acreditava, cercava a instituição.

Ainda no mesmo ano de sua eleição, Niomar faria publicar no Correio da Manhã reportagem sobre as mudanças que vinham ocorrendo no MAM. Na matéria redigida por Yvonne Jean com base em entrevista concedida por Castro Maya, a jornalista enfatizaria, sobretudo, a mudança da sede do Museu, que saía do alto das salas do Banco Boavista para se aproximar do público no anexo construído especialmente para a instituição sob os pilotis do prédio do Ministério da Educação e Cultura (MEC), também no centro da cidade. Chamava ainda a atenção para a luta pela sede própria e para a história dos primeiros anos de criação do Museu (Jean, 1951b). A entrevista, omitindo a eleição de Niomar, seria o estopim da ruptura entre Castro Maya e a nova diretora e acabaria por detonar uma profunda peleja da qual Niomar sairia vencedora, impondo no Museu a série de descontinuidades que fariam, para ela, uma imagem de museu moderno. Em tudo distante do colecionismo de diletantes que, para Niomar, caracterizava a primeira fase do museu, o MAM passaria, de fato, por uma série de descontinuidades propositalmente marcadas para fazer associar diretora e instituição. O discurso efetivamente eficaz faria com que os primeiros anos do Museu chegassem a ser mesmo, por vezes, esquecidos e com que a sua história passasse a ser narrada a partir de $1951 .^{1}$

A mudança de sede seria, de fato, um marco da nova gestão Niomar, dando visibilidade pública ao Museu, que passava a se localizar no térreo do prédio do MEC e que mais tarde construiria o edifício, ícone da arquitetura modernista de Afonso Eduardo Reidy, no recém-criado Aterro do Flamengo. No 
entanto, para além do espaço físico, uma série de inovações passariam a compor a nova imagem da instituição na gestão de Niomar.

Em lugar das práticas institucionais de Castro Maya, que se apoiavam nas relações de amizade para conseguir sedes, obras e exposições, Niomar estabeleceria uma rotina clara de organização que permitiria prever custos e angariar recursos. O pagamento dos sócios se faria de modo profissional a partir da contratação de um cobrador especialmente encarregado do assunto e, em 1957, Niomar Moniz Sodré viajaria aos Estados Unidos e lá fundaria uma sociedade de amigos do Museu de Arte Moderna do Rio de Janeiro. Os fundos angariados seriam divulgados em inúmeros periódicos e apareceriam seguidos das manchetes mais otimistas.

Também o espaço exibitório passaria a abrigar uma gama cada vez mais variada de exposições. Uma nova concepção de museu surgia baseada na ideia de que ao público não bastava mais visitar o acervo, era preciso que houvesse permanente renovação do mesmo. Se, até 1951, a marca do Museu havia sido dada pela exposição permanente, enfatizando as doações e iniciativas individuais do grupo de conhecidos de Castro Maya que haviam tornado possível a coleção do Museu, a partir do ano seguinte a ênfase da instituição recairia sobre as exposições temporárias, que passariam de duas por ano, entre 1948 e 1951, para mais de dez por ano no período que vai de 1952 a $1958 .^{2}$

Além de exposições temporárias para serem exibidas no Museu, entre 1952 e 1958 o MAM organizaria, ainda, uma série de exposições itinerantes, que deveriam percorrer o mundo exibindo a moderna arte brasileira: Exposição de arquitetura contemporânea (1954-1957), Gravadores brasileiros (1955), Pintura moderna brasileira (1956), Almir Mavignier (1956), Paisagista Roberto Burle Marx (1956), Exposição de arte moderna brasileira (1959-61) são alguns dos títulos recebidos pelas exposições itinerantes do MAM. Levadas a Viena, Utrecht, Madri, Lisboa, Berna, Zurique, Montevidéu, as exposições deixavam claro o intuito de exibir o que havia no país de mais alinhado com a moderna arte mundial.

Em múltiplos sentidos o Museu de Arte Moderna se estabelecia como uma rotina de exposições que visava, sobretudo, a aproximação com o público. Niomar Moniz Sodré dava concretude a um novo modelo de museu baseado menos na manutenção de um acervo permanente, como lugar de memória, que em exposições temporárias, eventos periódicos, palestras e num forte departamento educativo que daria a feição mais claramente pública da instituição.

Com efeito, os cursos de formação artística teriam início no Museu em 1952. Inseridos na "nova fase" do MAM, vinham, juntamente com as mudanças estabelecidas por Niomar, tentar concretizar a relação entre o público e a arte. A "conquista" da compreensão da arte moderna pressupunha, neste momento, também a conquista do fazer da arte moderna (Jean, 1951a).

Assim, os boletins do Museu anunciavam, em todos os seus números, as aulas de pintura ministradas por Ivan Serpa e Milton Goldring, e de modelagem, 
ministradas por Margareth Spencer. As aulas aconteciam inicialmente no prédio do Instituto de Previdência e Assistência dos Servidores do Estado (IPASE) e, até a construção da sede definitiva do Museu, ocupariam de barracões de obras a salas improvisadas, segundo referências na memória da instituição (Santos, 1999).

Nos primeiros anos as dificuldades eram patentes. Em carta a Niomar Moniz Sodré sobre a situação das aulas no barracão de obras do Museu, escreveria Mathilde Pereira de Sousa, administradora da instituição:

[...] tornam-se quase impossível os cursos teóricos, pois o barulho da máquina é tremendo. Recebi diversas reclamações. Falei com o Dr. Nelson, que me aconselhou a mudar o horário dos cursos, o que infelizmente não é possível, para o professor, nem para os alunos. A infiltração continua na cantina. [...] Os banheiros continuam incompletos (Sousa, 1958).

A conversa prosaica é tanto mais digna de nota na medida em que, ao chamar a atenção para a dificuldade em dar prosseguimento às aulas, salienta a continuidade que se dava a despeito de todos os problemas. Com efeito, apesar dos recorrentes entraves, o Museu diversificava os cursos e as turmas de sua programação. Em lugar do arrefecimento das aulas oferecidas, parecia haver, ao contrário, um aumento contínuo da programação. Em 1952, o anúncio nos Boletins, publicações periódicas do Museu, prometia, além dos cursos já oferecidos, "outros que ainda se [iam] formar" (Boletim, 1952) e, realmente, em 1955, o MAM contaria com novos cursos: Básico de Desenho (André LeBlanc), Iniciação e Orientação (Zélia Salgado), Desenho Estrutural e Composição (Tomás Santa Rosa), Decoração de Interiores (Wladimir Alves de Souza).

Era, contudo, Ivan Serpa quem sempre se destacaria na programação do Museu. Em 1952, à época da abertura de seus ateliês, o artista já havia sido premiado na I Bienal de São Paulo (1951), já lecionava em sua casa desde 1947 e ocupava lugar de relativo destaque nas críticas da imprensa nacional.

Assim, nos instrumentos de divulgação do MAM, as exposições dos trabalhos de suas turmas infantis recebiam especial destaque e seu nome aparecia correntemente no noticiário dos boletins. Em janeiro de 1953, o Boletim do Museu de Arte Moderna dedicaria grande espaço a uma série de reportagens do Correio da Manhã intitulada "O Professor Ivan Serpa":

Os cursos para adultos são frequentadíssimos.

Durante três meses o trabalho é de imaginação. Depois vem a hora do modelo: o aluno organiza a composição e pinta.

Pintor abstrato, Ivan não força ninguém a seguir a escola abstracionista que não deseja destruir os seus alunos, cuja personalidade respeita, mas ajudar a realizarem-se. [...]

Não é verdade que ele não admite a figura. Admite, sim, quando o artista se expressa através do modelo. $O$ que é preciso é que não se fique dominado pelas formas exteriores; o que é preciso é que saia alguma coisa de dentro. ${ }^{3}$ 
Ao dar relevância ao processo de aprendizado, a reportagem chamava a atenção para a dimensão formativa implícita nos cursos. Nivelando "alunos, cuja personalidade respeita", e o "artista [que] se expressa através do modelo", a narrativa deixava clara a linha de continuidade que existia entre o aprendizado e o fazer artístico. Não se tratava de uma escola de diletantes, de artistas de fim de semana, ou de artistas não profissionais (Becker, 1982), tratava-se, antes, de um espaço onde se aprenderiam técnicas, formas de expressão e modos legítimos de fazer arte; mecanismos sociais que fazem a identidade do artista (Dabul, 2001). E, com efeito, a profissionalização do artista seria a marca do projeto pedagógico do MAM, atraindo um público especialmente interessado em instituir novas formas de fazer arte.

O caráter pedagógico do MAM, embora faça eco à difusão de políticas museológicas educativas que começaram a se forjar no pós-guerra, parece dar especial diferenciação ao Museu. Ao olhar o modo como o MoMA, por exemplo, constituiu seu departamento de educação no mesmo período, algumas diferenças saltam imediatamente aos olhos. É verdade que na instituição nova-iorquina as salas de aula recebiam, também, lugar de destaque. Destinados a adultos e crianças, os cursos do MoMA apareciam como o espaço privilegiado de construção do saber acerca da arte moderna. Atendendo à demanda de um público ávido desse saber, o MoMA se propunha a "desenvolver os interesses criativos das pessoas, velhas e jovens e a ajudar a enriquecer sua vida cotidiana através do entendimento da arte de nosso tempo" (D’Amico, 1951, tradução minha). Contudo, o objetivo do MoMA, longe de visar à formação de novos artistas, parecia buscar transformar a percepção de mundo do homem comum. Segundo Victor D'Amico, chefe do departamento de educação do MoMA, a demanda pela expressão criativa deveria ser respondida com conhecimento:

A mãe orgulhosa, como muitos outros pais que querem exibir o trabalho de seus filhos, precisa entender as armadilhas de exibir o trabalho de crianças e o modo como isso pode enrijecer a habilidade criativa de seu filho a menos que seja dirigido com muito cuidado, com ênfase no processo criativo em lugar do produto final. A mãe que busca uma boa aula de arte para seus filhos é, na verdade, uma vítima de falsa economia por parte dos administradores da escola que olham para a arte como frivolidade, enquanto o advogado que quer aulas de arte seria provavelmente desencorajado se fosse submetido aos métodos laissez faire de um grupo de hobby (D’Amico, 1951, tradução minha).

Em lugar de educar seu público para a produção de arte, descobrindo talentos onde pareciam escondidos, a tarefa do Museu, com relação a seu público, residia em ensinar uma nova percepção de mundo a seus alunos. Em vez de buscar novos artistas, o MoMA visava a formar homens capazes de entender o seu mundo e, neste sentido, a criatividade era palavra de ordem. Se, para o Museu carioca, a experimentação para a criação de uma nova forma artística parecia ser a dimensão mais importante de sua escola e a exposição do tra- 
balho dos alunos era parte natural do aprendizado de um métier, para Victor D'Amico, a chave de entendimento da dimensão pedagógica do MoMA parecia estar alojada em sua capacidade de gerar "indivíduos criativos".

Ao pensar a modernidade como horizonte possível e futuro a ser construído, o MAM, sob o comando de Niomar Moniz Sodré, centrar-se-ia na agência e, assim fazendo, buscaria especialistas que se fossem formando junto com a instituição, jovens artistas formados para serem imediatamente exibidos. As escolhas em que a instituição se baseava partiam do princípio de que o mundo a ser feito no futuro o seria a partir do que se tinha aqui e agora.

Não se tratava de esperar o moderno acontecer para colher os seus frutos, mas de fazê-lo efetivamente operar, reconhecendo, imediatamente, nos agentes do novo, os especialistas do futuro. Acreditando que a modernidade era resultado de ideias passíveis de mudar o mundo uma vez que fossem formadas, o MAM pôde acreditar-se capaz de forjar seus próprios artistas e suas próprias vanguardas. No período, as aulas de Ivan Serpa deram origem ao Grupo Frente, fortemente associado ao Museu (Sant'Anna, 2008) e sua Cinemateca, foi responsável por criar um público e movimentos de ruptura no cinema nacional (Pougy, 1996). O Museu e a modernidade brasileira, não sendo encarados como resultado de um processo espontâneo a ser seguido por colecionadores e especialistas, foram, ao contrário, investidos do poder de fazer a ordem moderna. Dotado de um projeto de modernidade em muito distinto do projeto do MoMA, vale voltar à Escola de Ulm para entender em que medida um conjunto de referências poderia ser acionado para dar origem à especificidade do MAM.

\section{O PROJETO PEDAGógico dA ESCOLA DE ULM}

Fundada em 1953, cinco anos depois da criação do Museu de Arte Moderna do Rio de Janeiro, a Escola Superior da Forma, construída como instituição privada em Ulm, no Sul da Alemanha, foi criada pela Fundação Geschwister-Scholl como parte do esforço de recuperação da Alemanha após a II Guerra Mundial. No discurso institucional, a fundação, concebida e dirigida por Inge Scholl-Aicher, foi instituída em homenagem a seus irmãos, Sophie e Hans Scholl, que durante a Guerra haviam participado da resistência ao nacional-socialismo hitlerista e sido executados pelo regime nazista em 1943. Fundadores do grupo Weiße Rose, antimilitarista e notadamente cristão, os irmãos eram, então, considerados como o símbolo da juventude alemã que se queria construir no futuro. O ideal político parece ter se revestido de ideais de reforma estética em 1952, quando Inge Scholl se casou com Otl Aicher, designer gráfico. Os dois, juntamente com Max Bill, fundariam a nova Escola Superior da Forma. A ideia do grau zero e da reconstrução alemã encontrava no design um meio de tomar materialidade. 
Embora a escola de Ulm tenha sido fundada cinco anos depois do momento inicial de criação do MAM carioca, fato é que, talvez, as drásticas mudanças ocorridas no modelo pedagógico do Museu no decorrer de seus primeiros anos de vida possam ser atribuídas ao contato estabelecido entre as duas instituições. De fato, não são poucos os registros desta relação nesse período.

O modelo proposto por Max Bill aparece citado pela primeira vez na documentação do Museu quando de sua visita ao Brasil, em 1953. O Boletim de julho daquele ano é praticamente todo dedicado ao trabalho do artista (Boletim, julho de 1953). A conferência e a palestra ministradas no Museu foram transcritas e publicadas (Boletim, julho de 1953) e um coquetel foi oferecido em sua homenagem.

Àquela altura, Max Bill já havia exposto e dado conferências em São Paulo, a convite de Pietro Maria Bardi, em 1950; já havia sido premiado na I Bienal de São Paulo em 1951, e uma de suas esculturas estampava a capa do catálogo da Exposição permanente, de 1953, do Museu de Arte Moderna do Rio de Janeiro. À época de sua visita ao MAM, o Boletim, de julho de 1953, o apresentaria como "o famoso escultor modernista Max Bill" e o "homem que está tentando reconstruir o Bauhaus". Seu nome contava com relativo prestígio, como atestam os ilustres convidados ao coquetel de sua recepção. Segundo o Boletim, “compareceram, além de elementos do mundo artístico, críticos de arte, jornalistas, a alta sociedade carioca e paulista, elementos do mundo oficial, notando-se, entre outros, o vice-presidente Café Filho, o senador Marcondes Filho, vice-presidente do Senado, ministros João Neves da Fontoura, Horácio Láfer e Simões Filho" (Boletim, julho de 1953).

Foi, portanto, à época de sua visita ao MAM e das conferências pronunciadas em 1953, que a ênfase dada à importância do artista pareceu recair sobre o projeto pedagógico da escola de Ulm e que se poderia ver uma possível relação entre este e aquele da Escola Técnica de Criação do Museu de Arte Moderna do Rio de Janeiro (posteriormente Escola Superior de Desenho Industrial - ESDI). Com efeito, nas duas conferências publicadas pelo Boletim do Museu de Arte Moderna de julho de 1953, não são poucas as referências à nova instituição alemã:

Max Bill disse que outra pergunta que lhe fazem é sobre a criação da nova Bauhaus em Ulm. E conta a história. Fora convidado para sair de Zurique e ir à Alemanha realizar duas conferências. Nesse país esteve em contato com elementos da resistência espiritual, que tinham fundado em Ulm uma escola, uma espécie de Escola Superior de Criação (artística naturalmente). Desses contatos resultou que Bill foi encarregado de fazer o projeto de uma nova escola nas bases da Bauhaus. Para esse fim está trabalhando, e o grupo também procura obter os fundos indispensáveis (Boletim, julho de 1953).

Ao ler o primeiro trecho em que o Boletim, transcrevendo a conferência de Max Bill, cita a nova escola de Ulm, algumas referências chamam imediatamente a atenção. Em primeiro lugar, o emprego do termo Escola Superior de 
Criação traz, sem dúvida, alguns elementos para reflexão. O termo, provavelmente traduzido do nome Hochschule für Gestaltung, como era designada a nascente escola de Ulm, dá indicações da recepção do projeto de Max Bill para constituir a escola do MAM.

A Hochschule für Gestaltung, numa tradução mais rigorosa, é correntemente denominada Escola Superior da Forma ou, se se quisesse, da Formação. Quis o tradutor, porém, ou o desavisado jornalista que documentava a conferência dada, ou mesmo Max Bill que falava em francês, que a escola se chamasse Escola Superior de Criação. Anos mais tarde, ao descrever o novo projeto do prédio do Museu no Boletim do MAM em homenagem à nova sede, Affonso Eduardo Reidy se referiria ao Bloco Escola como o lugar onde funcionaria a Escola Técnica de Criação do MAM (Boletim, 1959). E, com efeito, o nome seria usado para designar o projeto de Carmem Portinho para a Escola do MAM, até que este se desvinculasse do Museu para tornar-se autônomo, como Escola Superior de Desenho Industrial. Não param, contudo, no nome as relações entre um e outro projeto. Na entrevista que se seguiu à conferência, transcrita pelo Boletim à época de sua visita ao Museu, Max Bill descreveria o projeto de Ulm. Diria ele:

Essa escola é a continuação do Bauhaus, um pouco à maneira do avião à reação que é a evolução do avião à hélice. Isto quer dizer que o princípio do voo permanece, e o princípio da energia se transforma um pouco.

O Bauhaus baseava-se ainda sobre o princípio da aliança das artes e da arquitetura. Nós já sabemos, por experiência, que esta base não é suficiente. Acrescentamos, então, à formação profissional a formação da personalidade mesma do estudante, para garantir à sua atividade futura uma influência tão grande quanto possível, no domínio da cultura de nossa idade técnica. Esperamos que esta elite vá formar cursos, para criar, por toda parte do mundo, centros com o mesmo espírito da nossa escola de Ulm, que é uma escola para apenas uma pequena elite. Ela só comporta 150 alunos, que vêm de diversos países.

As seções do plano de educação, que formam um círculo, são arquitetura, urbanismo, criação de objetos, criação visual, informação. A base dessas seções é um curso de formação fundamental, no qual o estudante adquire conhecimentos criativos no mais vasto plano. É impossível falar mais sobre essa questão, que atualmente é muito importante. Perderíamos muitos dias para dar explicações sobre os pontos do estatuto, o programa, eu poderia ter-me baseado sobre as experiências do Bauhaus de Gropius e sobre as experiências que eu próprio fiz. Entretanto, trabalhamos aqui durante três anos na elaboração dos estatutos da escola e ainda não paramos de modificá-lo (Boletim, julho de 1953).

A evocação da Bauhaus, da função profissional e espiritual da escola, sua correspondência à "idade técnica" são algumas categorias que estariam também na base de fundação do projeto da Escola Técnica de Criação do Museu de Arte de Moderna. Com efeito, a estreita relação entre a formação de artistas e a construção de um horizonte futuro, são elementos que possibilitaram o diálogo entre os dois projetos. 
De um lado, em 1953, Max Bill falava na "formação da personalidade mesma do estudante, para garantir à sua atividade futura uma influência tão grande quanto possível, no domínio da cultura de nossa idade técnica". De outro lado, em 1958, falando da Escola do MAM, Flexa Ribeiro chamava a atenção para a ideia de "educação integral de indivíduos, para realizar um trabalho inovador nos dois sentidos: no domínio das comunicações visuais entre os homens e no terreno do equipamento material da vida moderna". ${ }^{4}$ Um e outro projeto pareciam certos de que a formação de profissionais para uma estética que entrasse na vida de fato das pessoas, poderia ser responsável pela criação de uma nova sociedade.

De um lado, a escola de Max Bill encontrava na nova forma os caminhos de reconstrução da Alemanha no pós-guerra. O diagnóstico da crise e o desejo de reconstrução (Wiederaufbau) buscaram na pedagogia e na estética os caminhos possíveis de começar de novo (Pechmann, 1951).

De outro lado, a Escola do MAM, buscando superar o "quadro de subdesenvolvimento econômico e de atraso cultural" (Boletim, julho de 1953) em que se inseria o país, encontrava no Museu e na educação artística as chaves para fazer um Brasil moderno. A ideia de tábula rasa se fazia mais uma vez presente, não para superar a destruição da guerra, mas as ausências de cultura e desenvolvimento que eram então diagnosticadas.

Se a Hochschule für Gestaltung se construía sobre os escombros da guerra, o MAM se construía sobre o passado de natureza que agora era preciso domar (Sant'Anna, 2005).

Uma e outra Escola se construíam com vistas ao futuro e se ancoravam sobre financiamentos e esforços de expansão norte-americanos dos primeiros anos de Guerra Fria. De um lado, o MAM, sem grande apoio financeiro dos Estados Unidos, mas com o apoio do MoMA, de que recebia o modelo em que se basear; de outro, a Escola de Ulm, sem apoio das mesmas instituições artísticas, ${ }^{5}$ mas com investimentos diretos do Escritório Norte-Americano de Alto Comissariado para a Alemanha (ver Buttenwieser, 1950 e 1951). Ambos pareciam se enquadrar nos moldes de democracia e modernidade do novo capitalismo do pós-guerra. Voltados para a produção da arte industrial, apoiavam-se num sentido educacional universalista, que encontrava na forma plástica o sentido do entendimento.

Com efeito, muitas poderiam ser as semelhanças que explicariam a ênfase dada pelo MAM à formação de profissionais técnicos para a estetização da vida. Que haja uma relação entre a Escola Superior de Desenho Industrial e a Escola de Ulm é caso que já foi, em outras ocasiões, investigado (Nobre, 1999, 2006). Contudo, ao voltar à questão do projeto pedagógico do MAM, que em meados dos anos 1950 foi capaz de criar jovens artistas e suas próprias vanguardas, pouca parece ser a relação entre Ulm, a Escola Técnica de Criação do MAM, orientadas para a formação de quadros profissionais para a indústria, e o ateliê 
de Ivan Serpa, voltado para a formação de artistas para a experimentação. Em entrevista concedida a Glaucia Villas Bôas e Nina Galanternick, para o filme Almir Mavignier: memórias concretas, Mavignier descreve seu primeiro contato com Max Bill. Ao relembrar seu desejo de estudar em Ulm, o artista diria que sua primeira tentativa de ingressar na Escola foi recebida com a negativa do diretor. Segundo ele, Bill dizia que Ulm não era para pintores românticos que iam estudar em Paris. Apenas após a intervenção de Mary Vieira o artista seria aceito na instituição. Com efeito, ao que tudo indica, os projetos de Ivan Serpa para a formação de artistas, fortemente acolhido pelo Museu, parece ter muito pouca relação tanto com a Escola de Ulm, quanto com os cursos do MAM, mais claramente associados à profissionalização do desenho industrial.

Criados já em 1952, um ano antes da visita de Max Bill, os cursos livres do MAM voltavam-se, sobretudo, para a conquista de soluções estéticas e expressividade individual. O discurso que lá se forjava, embora estivesse ligado aos conceitos universalistas da abstração geométrica, buscava neles um vocabulário gráfico para a liberdade de experimentação. As aulas de Ivan Serpa, ainda que se tenham traduzido nas obras concretistas de muitos dos membros do Grupo Frente, ancoravam-se na ideia de formação livre e pessoal.

A ênfase conceitual de Max Bill na Escola, no trabalho anônimo do artesão parecem ter efetivamente recebido muito pouca adesão do projeto didático de Serpa. Liberdade de criação e expressividade parecem ser categorias cunhadas no léxico dos ateliês do Museu carioca. Com efeito, para os artistas do concretismo carioca, o nome do artista suíço chegaria mesmo a tornar-se sinônimo de rigidez e dogmatismo. Em 1982, diria Aluísio Carvão:

Tudo que não fosse cor primária, que não fosse Max Bill, era traição, especialmente para o pessoal de São Paulo, Cordeiro em particular. Este chegou a referir-se a mim como um surrealista, pelo simples fato de usar cores complementares. Ora, isso me parecia uma limitação; eu sempre reagi ao emprego unicamente das cores puras. Tinha minhas vivências e, às vezes, queria empregar um violeta intenso posto em confronto com um azul (Morais, 1982).

Assim, o ateliê livre permaneceria no Museu por toda a década de 1950, sobrevivendo mesmo à autonomia conferida à ESDI em 1963. Marcava-se, então, a distinção entre os dois projetos. Embora sejam notáveis as referências ao seu trabalho no projeto de formação de uma vanguarda concretista (Gullar, 1999; Pedrosa, 1998) e seu nome apareça na memória do movimento como importante influência, ${ }^{6}$ pouca parece ter sido de fato a relação de Max Bill com a criação de uma escola de formação artística para a ruptura no MAM.

Embora esteja estreitamente ligado ao projeto de criação de uma escola de desenho industrial no Museu, o projeto de Max Bill para a Escola de Ulm em muito se distingue daquele que já vinha sendo executado pela instituição carioca. Não é por acaso que, ao deixar a guarda do Museu, o projeto da ESDI deixa de associar-se à instituição e passa a ser encampado, sobretudo, por Carmem Portinho. 
Assim, ainda que ambos pertencessem aos projetos relativos aos primeiros anos do MAM, os "ateliês livres" e os cursos da "Escola Técnica de Criação" apareciam como modelos educacionais distintos. Por oposição a livres experimentos da criação artística, haveria de ser criada uma escola de profissionais. Ao aprendizado da técnica, que deveria se dar em âmbito universitário, desvinculado do fazer artístico, pareciam corresponder formações estanques de carreiras próprias, separadas das Belas Artes, da Arquitetura e também da Engenharia.

A vocação didática do MAM, embora tenha por vezes se confundido com o projeto de fundação da Escola Técnica de Criação, parecia supor uma clara distinção entre a formação de artistas e a formação de técnicos. O Museu concedia, assim, aos primeiros o espaço da vanguarda e aos segundos reservava o lugar de uma estetização pragmática da vida.

\section{CONSIDERAÇÕES FINAIS}

Ao dar início a este artigo, procurei entender em que medida a ideia de grau zero e tábula rasa, inscrita no pós-guerra alemão e institucionalizada na Escola de Ulm, poderia fazer sentido para uma elite intelectual que, nos anos 1950, acreditava construir o país como um projeto moderno, procurando apagar as sobreposições de natureza e cultura que haviam constituído sua identidade até antão. Procurei entender em que medida foi possível construir um horizonte de entendimento entre os fundadores da Escola de Ulm e os rotinizadores do Museu de Arte Moderna do Rio de Janeiro.

Embora de fato o diálogo tenha se estabelecido, ao comparar as instituições, no entanto, salta aos olhos que a relação arte-público apresenta, em cada caso, diferentes encaixes. De um lado, a Escola de Ulm, atribuindo à profissionalização técnica a possibilidade de reforma da personalidade; de outro lado, o MAM, atribuindo-se uma missão social, procurava fazer formar artistas para a produção de uma subjetividade mais moderna, com base em princípios de individuação e inovação. Dificilmente se poderia sustentar que a Escola de Ulm e o MAM fossem instituições idênticas, ou que o último fosse cópia da primeira. As diferenças eram patentes e pareciam ser devedoras da forma como a modernidade era concebida em cada um dos casos. Não porque o moderno supusesse um hiato de desenvolvimento, implicando aqui atrasos e ausências, mas porque era entendido de modos diferentes e, assim sendo, era capaz de operar no mundo de modos também distintos.

Por oposição aos processos necessários, o que sugiro, portanto, é que, para além de um conjunto de condições materiais ou de uma nova ordem de pensamento, a modernidade se pôs no mundo como categoria, que poderia ser interpretada de maneiras diversas e, em assim sendo, ganhar materialidade e repercussão, operando aqui e agora. Mudanças, em maior ou menor escala fa- 
zem parte da condição do próprio tempo. Que a modernidade fosse, no entanto, nomeada e diagnosticada como processo foi o que a transformou num universal passível de comunicação, de interpretação e de operacionalidade. Num certo sentido, MAM e Escola de Ulm foram, portanto, modos de entender o moderno e de dar a ele concretude no mundo; formas materiais de diálogo e discussão.

Artigo recebido para publicação em agosto de 2011.

Sabrina Parracho Sant'Anna é doutora em Sociologia pela Universidade Federal do Rio de Janeiro (UFRJ), professora do Departamento de Ciências Sociais e do Programa de Pós-Graduação em Ciências Sociais da Universidade Federal Rural do Rio de Janeiro (UFRRJ) e autora de Construindo a memória do futuro: uma análise da fundação do Museu de Arte Moderna do Rio de Janeiro (2011). Seus interesses de pesquisa incluem sociologia da arte, instituições de memória e a discussão das relações entre cultura e cidade. 


\section{NOTAS}

1 Flávia Bessone Corrêa (2001) e Carmem Portinho (apud Magalhães, 2005), por exemplo, indicam 1951 como o ano de fundação do Museu e apontam Niomar como a pessoa que o inaugurou.

2 Segundo dados coletados nos arquivos do MAM.

3 Reportagem de Flávia da Silveira Lobo, Correio da Manhã, 7 a 14 de dezembro de 1952. Ver Boletim (janeiro de 1953).

4 Seminário de estudos da Unesco sobre a função educativa dos museus: discurso do professor Carlos Flexa Ribeiro, do Museu de Arte Moderna do Rio de Janeiro, setembro de 1958. Boletim do Museu de Arte Moderna. Rio de Janeiro, janeiro de 1959.

5 Na documentação do Museu de Arte Moderna de Nova York, a única referência a Max Bill ou à Escola de Ulm é uma carta datada de 6 de julho de 1963. Trata-se de uma reposta à carta escrita por Max Bill a Alfred Barr, informando-o de sua estadia em Nova York e de uma possível visita ao Museu. Ao contrário da calorosa acolhida recebida no Rio de Janeiro, Max Bill encontraria, em resposta, carta de Marie Alexander, secretária, informando que Alfred Barr estaria deixando a cidade no mesmo dia da chegada do artista. Enviava ainda, em todo caso, um ingresso de admissão complementar, com o qual poderia entrar no Museu em qualquer momento de sua conveniência. Para além dos desejos de uma visita satisfatória, não havia menção a qualquer tipo de recepção especialmente preparada para sua chegada. Ao que parecia, o Museu sequer designara um funcionário para recebê-lo. Ver Carta de Marie Alexander a Max Bill, 6 de julho de 1963. Microfilme. Rolo 2181 - frame 1214. Arquivos do Museu de Arte Moderna de Nova York.

6 "Discutíamos - eu, Serpa, Almir Mavignier, Palatnick, Lygia Clark etc. - Mondrian, Max Bill, questões de espaço, cor, tempo. Eram discussões muito intensas, nas quais se cobravam do outro posições. Cheguei ao grupo por afinidades com as preocupações em torno de um novo espaço" (Depoimento de Aluísio Carvão, O Globo, 27 de junho de 1990). 


\section{REFERÊNCIAS BIBLIOGRÁFICAS}

Andrade, Rodrigo Mello Franco de. Carta de Rodrigo Mello Franco de Andrade a Raymundo Ottoni de Castro Maya, 12 de maio de 1950.. Arquivos da Fundação Castro Maya. MAMIII. Pasta 69, doc. 15.

Arruda, Maria Arminda do Nascimento. Metrópole e cultura: São Paulo no meio do século XX. São Paulo: Edusc, 2001.

Becker, Howard. Art worlds. Berkeley: University of California Press, 1982.

Boletim do Museu de Arte Moderna. Rio de Janeiro, novembro de 1952; janeiro de 1953; julho de 1953; janeiro de 1959.

Alexander, Marie. Carta de Marie Alexander a Max Bill, 6 de julho de 1963. Arquivos do Museu de Arte Moderna de Nova York, Microfilme. Rolo 2181, frame 1214.

Buttenwieser, Benjamin J. Cartas de Benjamin J. Buttenwieser a Inge Scholl, 29 de dezembro de 1950 e 23 de maio de 1951. Ulm, Hochschule für Gestaltung Archive.

Corrêa, Flávia Rocha Bessone. De coadjuvantes a protagonistas: a trajetória de três mulheres que trocaram os salões de sociedade pelo controle de grandes jornais brasileiros nas décadas de 50 e 60. Dissertação de Mestrado. PPGHSC/Pontifícia Universidade Católica do Rio de Janeiro, 2001.

Dabul, Lígia. Um percurso da pintura: a produção de identidades de artista. Niterói: Eduff, 2001.

D'Amico, Victor. Creative art. Bulletin of the Museum of Modern Art. Nova York, outono de 1951.

Durand, José Carlos. Arte, privilégio e distinção. São Paulo: Perspectiva, 1989.

Gullar, Ferreira. Etapas da arte contemporânea: do cubismo à arte neoconcreta. 3. ed. Rio de Janeiro: Revan, 1999.

Jean, Yvonne. O desenvolvimento dos Museus de Arte no país. Correio da Manhã, 15 de junho de 1951a.

O Museu de Arte Moderna do Rio: Raymundo Castro Maya fala no futuro do museu e relembra atividades passadas. Correio da Manhã, 12 de agosto de 1951b.

Magalhães, Ana Maria. Lembranças do futuro. Parte II. Documentário. Rio de Janeiro: Nova Era Produções de Arte, 2005. 
MAM. Pintura Europeia Contemporânea. Catálogo de Exposição. Rio de Janeiro, 1949.

Morais, Frederico. Entrevista de Aluísio Carvão: Quando a pintura toma novo impulso. O Globo, $2^{\circ}$ Caderno, 5 de novembro de 1982.

Nobre, Ana Luiza. Carmem Portinho. Rio de Janeiro: Relume Dumará, 1999.

A ESDI e a estruturação do meio do Design no Brasil. Anais do III Seminário de Sociologia da Cultura e da Imagem. NUSC/Universidade Federal do Rio de Janeiro, 2006.

Parada, Maurício. A fundação do Museu de Arte Moderna do Rio de Janeiro: a elite carioca e as imagens da modernidade no Brasil dos anos 1950. Dissertação de Mestrado. PPGHSC/Pontifícia Universidade Católica do Rio de Janeiro, 1994.

Pechmann, Günther V. Bericht uber den Plan des Forschungsinstitutes und die Hochschule für Gestaltung. Ulm, Hochschule für Gestaltung Archive, 27 de junho de 1951.

Pedrosa, Mario. Acadêmicos e modernos. São Paulo: Edusp, 1998.

Pougy, Alice. Cinemateca do MAM e os cineclubes do Rio de Janeiro: formação de uma cultura cinematográfica na cidade. Dissertação de Mestrado. PPGHSC/ Pontifícia Universidade Católica do Rio de Janeiro, 1996.

Sant'Anna, Sabrina Parracho. A paisagem moderna de Mario Pedrosa (1949-1959): Natureza Concretista?. Achegas.net, 2005, 23, p. 23.

Construindo a memória do futuro: uma análise da fundação do Museu de Arte Moderna do Rio de Janeiro. Tese de Doutorado. PPGSA/ Universidade Federal do Rio de Janeiro, 2008.

Santos, José Roberto Marcellino (coord.). Museu de Arte Moderna do Rio de Janeiro. Texto de Brito, Maria Regina do Nascimento; Farias, Agnaldo \& Zílio, Maria Del Carmen. São Paulo: Banco Safra, 1999.

Seminário de estudos da Unesco sobre a função educativa dos museus: discurso do professor Carlos Flexa Ribeiro, do Museu de Arte Moderna do Rio de Janeiro, setembro de 1958. Boletim do Museu de Arte Moderna. Rio de Janeiro, janeiro de 1959. 
WIEDERAUFBAU NO BRASIL: RELAÇÕES ENTRE A ESCOLA DE ULM E O PROJETO PEDAGÓGICO DO MAM CARIOCA

200

Souza, Mathilde Pereira de. Carta de Mathilde Pereira de Souza a Niomar Moniz Sodré, 3 de abril de 1958. Rio de Janeiro, Correspondência de Niomar Moniz Sodré, Arquivos do Museu de Arte Moderna do Rio de Janeiro.

Villas Bôas, Glaucia \& Galanternick, Nina. Almir Mavignier: memórias concretas. Filme documentário. Rio de Janeiro, 2006, $27 \mathrm{~min}$. 


\section{Palavras-chave: Resumo:}

Museu de Arte Moderna; Escola de Ulm; Modernidade;

Modernização brasileira; Rio de Janeiro.

Keywords:

Museum of Modern Art; Hochschule für Gestaltung; Modernity; Brazilian modernization; Rio de Janeiro.
Ao procurar entender a fundação do Museu de Arte em face do processo de modernização brasileira de meados do século XX, a busca de referências estrangeiras na concepção do museu tem sido caminho obrigatório para as investigações sobre a instituição. As constantes referências à escola de Ulm e à inspiração que poderia ter proporcionado a seu caráter didático conduzem a uma possível comparação que procuro estabelecer neste artigo. A Escola de Ulm aparece como importante referência para o modo como o MAM carioca construiu seu modelo pedagógico, constituindo, quem sabe, a base das especificidades que marcaram a relação do museu com seu público.

\section{Abstract:}

In seeking to understand the foundation of the Museum of Art in the context of the Brazilian modernization process in the mid-twentieth century, the pursuit of foreign references in forging the museum has been the obligatory path to the investigations of the institution. The constant references to the Ulm Hochschule für Gestaltung and the inspiration that could have provided the didactic character of the institution can lead to the comparison that I seek to establish in this article. The Hochschule für Gestaltung is seen here as an important reference for the MAM Rio and the pedagogical model established in the first decade of the museum, possibly providing the ground for the specificities that characterized the relationship between the museum and its audience. 